\title{
Bioconjugation of Supramolecular Metallacages to Integrin Ligands for Targeted Delivery of Cisplatin
}

Jiaying Han, ${ }^{[a], \dagger}$ Andreas F. B. Räder, ${ }^{[b]}, \dagger$ Florian Reichart, ${ }^{[b], \dagger}$ Brech Aikman, ${ }^{[c]}$ Margot N. Wenzel,[c] Benjamin Woods, ${ }^{[c]}$ Michael Weinmüller, ${ }^{[b]}$ Beatrice S. Ludwig, ${ }^{[b]}$ Stefan Stürup, [d] Geny M. M. Groothuis, ${ }^{[a]}$ Hjalmar P. Permentier, ${ }^{[a]}$ Rainer Bischoff, ${ }^{[a]}$ Horst Kessler, ${ }^{[b]}{ }^{*}$ Peter Horvatovich, ${ }^{[a]{ }^{*}}$ and Angela Casini[c]*

$\dagger \quad$ Authors contributed equally to the work.

[a] Groningen Research Institute of Pharmacy, University of Groningen, Antonius Deusinglaan 1, 9713 AV Groningen, The Netherlands.

[b] Institute for Advanced Study and Center of Integrated Protein Science München (CIPSM), TU München, Department Chemie, Lichtenbergstr. 4, 85747 Garching, Germany.

[c] School of Chemistry, Cardiff University, Main Building, Park Place, CF10 3AT Cardiff, United Kingdom.

[d] Dept. of Pharmacy, University of Copenhagen, Universitetsparken 2, 2100 Copenhagen, Denmark.

Corresponding authors' emails:

casinia@cardiff.ac.uk; p.l.horvatovich@rug.nl; kessler@tum.de

\begin{abstract}
Cisplatin occupies a crucial role in the treatment of various malignant tumours. However, its efficacy and applicability are heavily restricted by severe systemic toxicities and drug resistance. Our study exploits the active targeting of supramolecular metallacages to enhance the activity of cisplatin in cancer cells while reducing its toxicity. Thus, $\mathrm{Pd}_{2} \mathrm{~L}_{4}$ cages $(\mathrm{L}=$ ligand) have been conjugated to four integrin ligands with different binding affinity and selectivity. Cage formation and encapsulation of cisplatin was proven by NMR spectroscopy. Upon encapsulation, cisplatin showed increased cytotoxicity in vitro, in melanoma A375 cells overexpressing av $\beta 3$ integrins. Moreover, ex vivo studies in tissue slices indicated reduced toxicity towards healthy liver and kidney tissues for cage-encapsulated cisplatin. Analysis of metal content by ICP-MS demonstrated that encapsulated drug is less accumulated in these organs compared to the 'free' one.
\end{abstract}




\section{Introduction}

Recently, supramolecular coordination complexes (SCCs) have attracted exploration in the fields of drug delivery, biomolecular recognition and imaging. ${ }^{1,2}$ Thus, the number of reports on the bioactivity of threedimensional SCCs with different shapes, including helicates, ${ }^{3}$ metallacages,,$^{4}$ cubes, ${ }^{5}$ prisms ${ }^{6}$ and capsules, ${ }^{7}$ and different compositions - $\left(\mathrm{Mn}_{\mathrm{n}}\right)$ where $\mathrm{M}$ is usually $\mathrm{Fe}(\mathrm{II}), \mathrm{Pd}(\mathrm{II}), \mathrm{Pt}(\mathrm{II})$, or half-sandwich organometallic clips based on $\mathrm{Ru}(\mathrm{II})$, Os(II), or Ir(III) and $\mathrm{Rh}(\mathrm{III})$, and L is the ligand of the coordination complex - has substantially increased. In this context, supramolecular metallacages offer several properties making them attractive candidates for future drug delivery systems. ${ }^{8}$ These discrete chemical entities, at variance with metal organic framework (MOFs), feature a secure cavity to host small drug molecules, while the ability to modify the ligand structure both pre- and post-self-assembly allows for fine tuning of the overall properties like solubility in aqueous environment. ${ }^{9}$ Despite these promising properties, the full potential of metallacages as drug delivery vehicles has not been explored so far. ${ }^{2}$

In 2012, Crowley and co-workers reported on the encapsulation properties of the anticancer drug cisplatin within $\mathrm{Pd}_{2} \mathrm{~L}_{4}$ cages ( $\mathrm{L}=2,6$-bis(pyridine-3-ylethynyl)pyridine as the bidentate ligand), studied by NMR and X-ray diffraction. ${ }^{10}$ Platinum-based anticancer drugs are the mainstay of chemotherapy regimens in clinic. Nevertheless, the efficacy of cisplatin is badly affected by serious systemic toxicities and drug resistance, and its pharmacokinetics is still under consideration. ${ }^{11}$

Therefore, cisplatin encapsulation in metallacages could enable a better delivery approach, minimizing the systemic toxicity of the drug while reducing its speciation. More recently, we explored similar cationic $\left[\mathrm{Pd}_{2} \mathrm{~L}_{4}\right]^{4+}$ systems and developed the exo-functionalization of the ligand scaffold to add different functionalities (e.g. fluorescent tags). ${ }^{12,13}$ Structural studies by ${ }^{1} \mathrm{H}$ NMR ad X-ray diffraction were performed demonstrating encapsulation of cisplatin. ${ }^{14,15}$ Furthermore, the cytotoxicity of the $\left[\mathrm{Pd}_{2} \mathrm{~L} 4\right]^{4+}$ cages have been tested in vitro against a small panel of human cancer cells, showing scarce or moderate antiproliferative activities depending on the ligand scaffold. ${ }^{15}$ However, in order to achieve tumour selectivity, we envisaged the conjugation of the cages to cancer-cell-specific ligands - such as used in virus-like particles ${ }^{16}$ - as the best strategy. Thus, we recently reported the first example of bioconjugation of self-assembled $\mathrm{Pd}_{2} \mathrm{~L}_{4}$ cages to a linear model peptide. ${ }^{17}$

Here we extended our investigation to the bioconjugation of the cages to integrin binding ligands. Integrins have been extensively studied as drug targets, interacting with the extracellular matrix (ECM) and thereby regulating many cellular functions, such as proliferation, migration, and survival. ${ }^{18,19}$ In mammals, there are eight $R G D$ recognizing integrin subtypes among them $\alpha v \beta 3$ and $\alpha 5 \beta 1$, expressed 
in cancer tissue and promoting tumour metastasis. ${ }^{19}$ Over the years, numerous small peptidic or peptidomimetic molecules were designed and used to selectively address various integrin sub-types to treat different pathologies or for imaging. ${ }^{20-26}$ As an example, the cyclic pentapeptide cyclo(RGDfV $)^{27}$ and the related Cilengitide ${ }^{28}$ were found to be potent ligands for the integrins $\alpha v \beta 3$, $\alpha v \beta 5$, and $\alpha 5 \beta 1 .{ }^{25,29}$

It is worth mentioning that direct tethering of integrin binding peptides to cytotoxic platinum complexes have been also reported. For example, Lippard et al. explored the targeting ability of linear and cyclic RGD and Asn-Gly-Asp (NGR) integrin targeting ligands, and synthesized a Pt(IV) series comprising mono- and difunctionalized complexes, which improved the cisplatin anticancer activity, once the $\mathrm{Pt}(\mathrm{IV})$ compound is reduced to cisplatin in the intracellular environment. ${ }^{30}$ More recently, other $\mathrm{Pt}(\mathrm{II})$ and $\mathrm{Pt}(\mathrm{IV})$ complexes, functionalized with cyclic and multimeric RGD-containing peptides, have been described. ${ }^{31,32}$ Interestingly, conjugation of a photoactivatable Pt(IV) prodrug to a cyclic RGDcontaining peptide, led to increased phototoxicity in melanoma cancer cells overexpressing the av $\beta 3$ integrin receptor. ${ }^{32}$ However, these targeting approaches do not address the problem of metallodrug speciation until the target is reached, and, therefore, possibilities of cisplatin encapsulation into a targeted drug delivery vector are extremely appealing.

Hence, we conjugated a $\mathrm{Pd}_{2} \mathrm{~L}_{4}$ metallacage to four integrin ligands for subtype specific targeting of integrin $a v \beta 3$ (compounds $1-3)^{26,27,33}$ or $\alpha 5 \beta 1$ (compound 4), ${ }^{34}$ respectively (Figure 1). ${ }^{23,24,35,36}$ Cage formation and cisplatin encapsulation were studied by NMR spectroscopy. The conjugated cages were first studied for their integrin recognition properties using an ELISA assay. Afterwards, the three cages targeted to $\alpha \vee \beta 3$ and encapsulating cisplatin were tested for their antiproliferative effects against two human cancer cell lines with different levels of integrin expression, namely the melanoma cell line A375 overexpressing $\alpha v \beta 3$, and the lung cancer cell line A549, deprived of this integrin. Moreover, the toxicity of a representative cage and of its encapsulated cisplatin was evaluated ex vivo in healthy tissues. Finally, the accumulation of cisplatin was also studied in tissues by Inductively Coupled Plasma Mass Spectrometry (ICP MS).

\section{Results and Discussion}

Initially, the ligand LO featuring a carboxylic acid group in exo-position has been synthesised adapting a previously reported procedure, ${ }^{12}$ to increase the overall yield and including a protecting step of the carboxylic moiety (See Experimental for details). Thus, LO was used for coupling to the aminofunctionalized integrin ligands 1-4 to form the cage precursors L1-L4 (Fig. 1). The products were 
analysed by various methods, including NMR spectroscopy (Figures S1-S7, S10-S11, S13-S14, S1617, S19-S20, SI). Afterwards, the cages $\mathbf{C} 0$-C4 were formed by self-assembly upon addition of 2 eq. of the $\mathrm{Pd}^{2+}$ precursor $\left(\mathrm{Pd}(\mathrm{MeCN})_{4}\left(\mathrm{BF}_{4}\right)_{2}\right)$, as proven by ${ }^{1} \mathrm{H} \mathrm{NMR}$ (Fig. S8-S9 and $\left.\mathrm{S} 12, \mathrm{~S} 15, \mathrm{~S} 18, \mathrm{~S} 21, \mathrm{SI}\right)$, and remained stable in solution for at least $24 \mathrm{~h}$.

In Figure 2, the stepwise addition of $\mathrm{Pd}^{2+}$ precursor to ligand $\mathbf{L} \mathbf{4}$ enabled following the selfassembly process leading to cage $\mathbf{C 4}$ formation by ${ }^{1} \mathrm{H}$ NMR spectroscopy. In details, to the free bioconjugated ligand $\mathbf{L} 4$ (4.00 eq. Figure $2 \mathrm{~A}), \mathrm{Pd}(\mathrm{MeCN})_{4}\left(\mathrm{BF}_{4}\right)_{2}$ was added in four portions $(0.50$ eq., Figure 2B-E). The adjacent protons of the metal binding site undergo a significant shift of about $1 \mathrm{ppm}$ ( $a$ to $a^{\prime}$ and $b$ to $b^{\prime}$ ) and also the two remaining protons of the pyridyl residue (e to e' and $f$ to $f^{\prime}$ ) slightly shift after binding of the $\mathrm{Pd}^{2+}$ ions. The more distant protons (c and d, and the protons of the integrin ligand) do not show any remarkable shift with binding of the $\mathrm{Pd}^{2+}$ precursor to form the cage $\mathbf{C 4}$ (Figure $2 \mathrm{E})$. The full consumption of the free ligand after an addition of 2.00 eq. $\mathrm{Pd}(\mathrm{MeCN})_{4}\left(\mathrm{BF}_{4}\right)_{2}$ clearly indicates a ratio of ligand to $\mathrm{Pd}$ of $2: 1$, which could be explained by the formation of cage $\mathbf{C} 4\left(\mathrm{Pd}_{2} \mathrm{~L} \mathbf{4}_{4}\right)$.

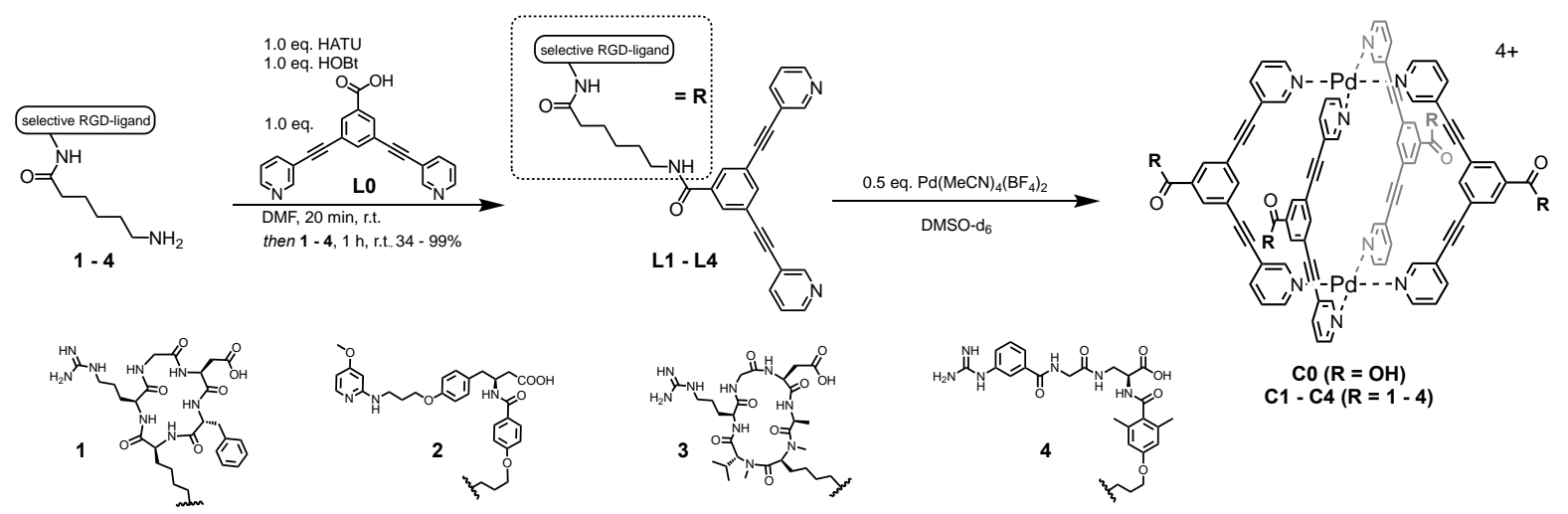

Figure 1. Synthesis of the bioconjugated ligands L1-L4 and of cages $\mathbf{C 0}$ and C1-C4 via metal-mediated self-assembly. (HATU $=$ hexafluorophosphate azabenzotriazole tetramethyl uronium, $\mathrm{HOBt}=$ hydroxybenzotriazole). Compounds 1-4 are the integrin binding ligands for $\alpha v \beta 3$ (1-3) and $\alpha 5 \beta 1$ (4). The integrin ligands were originally described in the following literature: $\mathbf{1}^{27,35}, \mathbf{2}^{24,33}, \mathbf{3}^{26}$, and $\mathbf{4}^{23,34}$. 

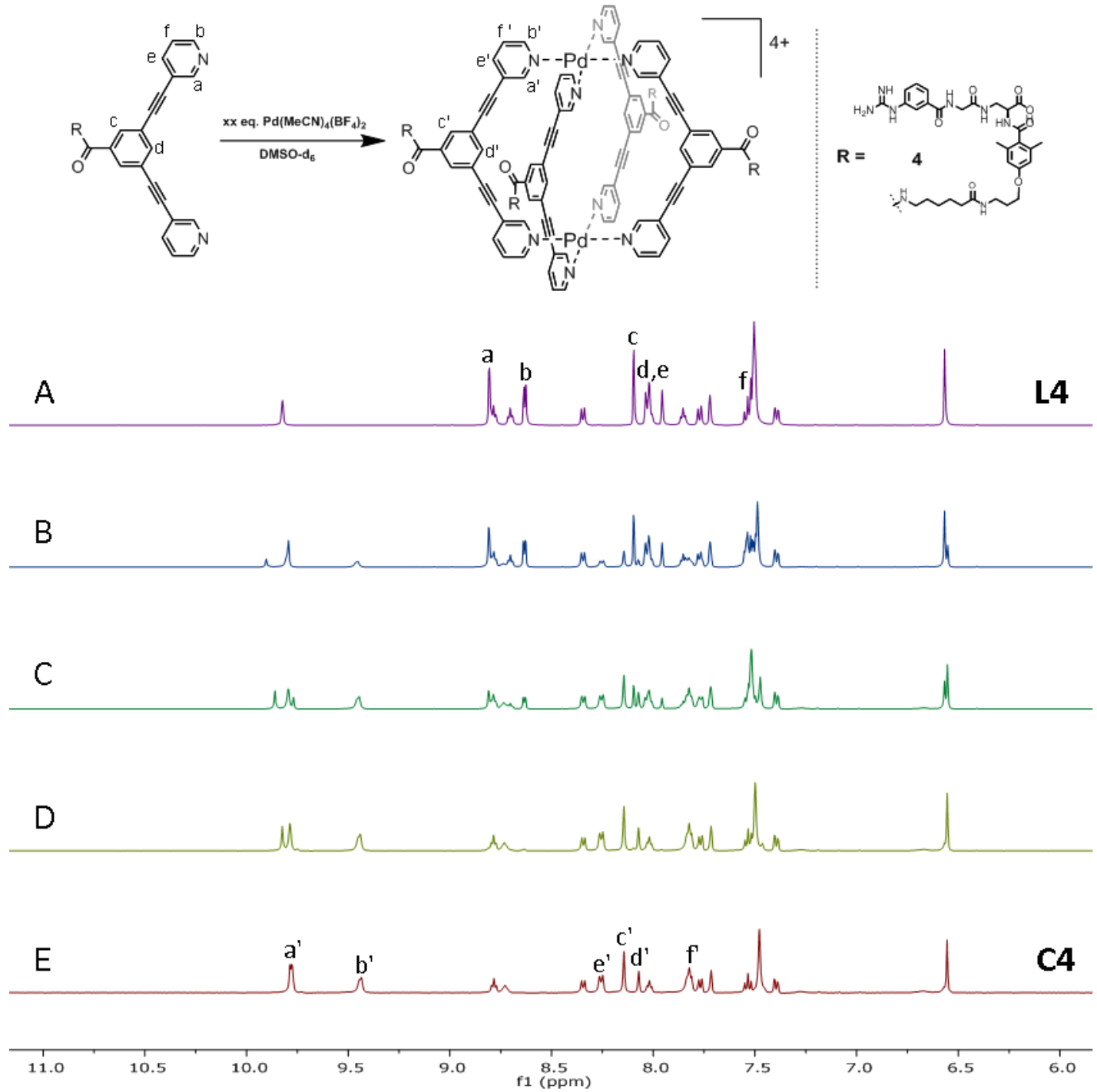

Figure 2. Titration of ligand $\mathbf{L} 4$ with $\mathrm{Pd}(\mathrm{MeCN})_{4}\left(\mathrm{BF}_{4}\right)_{2}$ and self-assembly process leading to formation of cage $\mathbf{C} 4$ followed by ${ }^{1} \mathrm{H}$ NMR spectroscopy. A. Spectrum of the bioconjugated metal ligand L4 (4.00 eq.) in DMSO-d6. Addition of the $\mathrm{Pd}\left(\mathrm{MeCN}_{4}\left(\mathrm{BF}_{4}\right)_{2}\right.$ (B. 0.50 eq.; C. 1.00 eq.; D. 1.50 eq.; E. 2.00 eq.; as a solution in DMSO-d6) results in the step-wise self-assembly of cage $\mathbf{C 4}$.

The bioconjugated cages C1-C4 as well as their precursors L1-L4 were assessed for their integrin binding affinity and selectivity by an established ELISA-like solid-phase binding assay. ${ }^{25,37}$ Data are reported in Table 1 and show that $\mathbf{C} 1-\mathbf{C} 3$ av $\beta 3$ and $\mathbf{C} 4$ a5 $\beta 1$ complexes feature strong binding, as expected from the original binding affinity of the parent ligands L1-L4, ${ }^{25}$ while the unsubstituted cage C0 exhibited no binding affinity at all. Compared to Cilengitide, ${ }^{28}$ the metallacages $\mathbf{C} 1-\mathbf{C} 4$ show higher selectivity for their target integrin with affinities in the low nanomolar range. The observation that multimerization is improving the binding affinity of ligands is well-known and often investigated, ${ }^{38,39}$ this was also found by us for RGD-containing ligands very early. ${ }^{40,41}$ The role of multimerization is especially important for integrins ${ }^{42}$ as multimeric integrin ligands might help to enter cells by endocytosis as it is 
used by viruses such as foot and mouth disease ${ }^{43}$ and used for virul-like-particles. ${ }^{16}$ Within the group of av $\beta 3$ active cages $\mathbf{C 1}-\mathbf{C} 3$, the nature of the integrin binding ligand has an influence on the discriminating selectivity towards the other integrins. Whereas the cyclic peptides in $\mathbf{C} 1$ and $\mathbf{C} 3$ show increased affinity for all integrins upon cage formation, the peptidomimetic $\mathbf{C 2}$ displays in addition an enhanced selectivity for its target integrin av $\beta 3$. The peptidomimetic $\alpha 5 \beta 1$ targeting cage $\mathbf{C 4}$, as well as the precursor L4, show very high selectivity for the integrin $\alpha 5 \beta 1$. The activity of $\mathbf{L} 4$ for $\alpha 5 \beta 1$ was far below $1 \mathrm{nM}$ and might additionally be attributed to any unspecific interaction between L4 and the integrin.

Table 1. IC $\mathrm{C}_{50}$ values of metallacages $\mathbf{C O}-\mathbf{C} 4$ and their ligand precursors L1-L4 for binding to RGDrecognizing integrin subtypes $\alpha 5 \beta 1, \alpha \vee \beta 3, \alpha \vee \beta 5$ and $\alpha \vee \beta 6$.

\begin{tabular}{|c|c|c|c|c|}
\hline & \multicolumn{4}{|c|}{$\mathrm{IC}_{50}[\mathrm{nM}]^{[\mathrm{a}]}$} \\
\hline compound & $\alpha 5 \beta 1$ & $\alpha v \beta 3$ & $\alpha v \beta 5$ & $\alpha \vee \beta 6$ \\
\hline $\mathrm{CO}$ & $>10000$ & $>10000$ & $>10000$ & $>10000$ \\
\hline C1 & $20 \pm 2$ & $2.1 \pm 0.8$ & $49 \pm 6$ & $159 \pm 18$ \\
\hline $\mathrm{C} 2$ & $1025 \pm 331$ & $0.98 \pm 0.24$ & $6580 \pm 911$ & $644 \pm 66$ \\
\hline C3 & $193 \pm 62$ & $0.38 \pm 0.01$ & $24 \pm 6$ & $13 \pm 2$ \\
\hline $\mathrm{C} 4$ & $1.77 \pm 0.15$ & $>10000$ & $>10000$ & $2370 \pm 303$ \\
\hline L1 & $215 \pm 71$ & $24 \pm 5$ & $147 \pm 9$ & $479 \pm 39$ \\
\hline L2 & $66 \pm 12$ & $3.3 \pm 1.3$ & $827 \pm 118$ & $148 \pm 11$ \\
\hline L3 & $396 \pm 127$ & $0.87 \pm 0.31$ & $156 \pm 20$ & $64 \pm 13$ \\
\hline L4 & $<1$ & $>1000$ & $>10000$ & $1361 \pm 151$ \\
\hline Cilengitide $^{[\mathrm{b}]}$ & $14.9 \pm 3.1$ & $0.61 \pm 0.06$ & $8.4 \pm 2.1$ & $2050 \pm 640$ \\
\hline
\end{tabular}

[a] The reported $\mathrm{IC}_{50}$ values were calculated using a sigmoidal fit to 16 data points, obtained from two serial dilution rows, by using Origin software package. All IC 50 values determined were referenced to the affinity of the internal standard and are presented as mean $\pm S D$. ${ }^{[b]} I C_{50}$ values of Cilengitide as previously reported. ${ }^{25}$

Previously reported results on unsubstituted $\mathrm{Pd}_{2} \mathrm{~L}_{4}$ cages showed that they are able to encapsulate two molecules of cisplatin as determined by X-ray diffraction and NMR spectroscopy. ${ }^{10,15}$ Thus, we also studied the cisplatin encapsulation properties of the protected cage $\mathbf{B z}-\mathbf{C O}$ by ${ }^{1} \mathrm{H}$ NMR (Fig. S22) and ${ }^{1} \mathrm{H}$ DOSY NMR (Fig. S23-S27). The use of the protected cage instead of cage $\mathbf{C 0}$ is due to its higher solubility in the selected NMR conditions. In the ${ }^{1} \mathrm{H}$ NMR spectrum in Fig. S22, the inward directed pyridyl proton signals undergo shifts upon encapsulation of 2 eq. of cisplatin, which are consistent with previously reported results. ${ }^{15}$ Specifically, $\mathrm{H}_{\mathrm{a}}$ undergoes a downfield shift of $\Delta \delta=0.0048$ ppm, and $\mathrm{H}_{\mathrm{b}}$ of $\Delta \delta=0.0148 \mathrm{ppm}$. Instead, for the benzyl proton $\mathrm{H}_{\mathrm{e}}$ an upfield shift of $\Delta \delta=0.114 \mathrm{ppm}$ was observed (Fig. S22). Furthermore, the titration of cisplatin (up to 2 eq.) to a cage solution shows 
marked differences in the ${ }^{1} \mathrm{H}$ DOSY NMR spectra of free cisplatin, due to its encapsulation (Fig. S23S27). Further addition of cisplatin (3 eq.) shows reappearance of the free cisplatin signals (Fig. S27). Formation of the host-guest complex was also supported by ${ }^{195} \mathrm{Pt}$ NMR spectroscopy where the disappearance of the classical Pt resonance of free cisplatin at $-2080 \mathrm{ppm}$ was observed upon addition of cage Bz-C0 (Figure S28).

To validate our targeting concept, the antiproliferative effects of the coordination cages $\mathbf{C 1 - C 3 ,}$ alone and encapsulating cisplatin [cisplatin $\subset($ C1-3)] were evaluated against two different cell lines with different $\alpha \vee \beta 3$ integrin expression pattern, in comparison to free cisplatin (see $\mathrm{SI}$ for experimental details). Specifically, the malignant melanoma cell line $A 375$ has been shown to overexpress $\alpha v \beta 3,44$ while the human lung cancer cell line A549 is reported not to express it. ${ }^{45}$ The latter cell type is also resistant to cisplatin. Thus, cells were treated with increasing concentrations of cages and ligands; concentrations higher than $60 \mu \mathrm{M}$ were usually not reached due to the toxic effect induced by the presence of DMSO, particularly in the A375 cells. Drug encapsulation in each cage system was assessed by ${ }^{1} \mathrm{H}$ NMR prior each experiment and confirmed encapsulation of 2 eq. of cisplatin per eq. of cage (data not shown). It should be mentioned that cisplatin stock solutions were freshly prepared in aqueous solution ( $1 \mathrm{mM})$ to avoid ligand exchange reactions with DMSO.

The results are summarized in Table 2 and show that cages C1-C3 alone are scarcely toxic to the two cell lines, while cisplatin is moderately toxic only in the $\mathrm{A} 375$ cells $\left(\mathrm{EC}_{50}=33.9 \pm 2.9 \mu \mathrm{M}\right)$. Moreover, while treatment with cisplatin encapsulated in the "untargeted" cage C0 ([cisplatin $\subset(\mathbf{C O})]$ ) does not change the drug's antiproliferative effects, cisplatin encapsulated in the bioconjugated cage C2 significantly increases its cytotoxic potency against the av $\beta 3$ integrin expressing A375 cells (ca. 2fold more potent with respect to free cisplatin). Instead, the same [cisplatinc(C2)] formulation does not increase the cisplatin toxicity against the A549 cells with no expression of av $\beta 3$. Concerning cages $\mathbf{C} 1$ and C3, none of them increase significantly the cytotoxicity of cisplatin in the A375 cell line, which could be related to the lower selectivity against $\alpha 5 \beta 1$ and/or av $\beta 5$ (Table 1). This result could also be due to differences in stability and drug release properties of the cages in the biological environment. Finally, it is worth mentioning that the $\mathrm{Pd}^{2+}$ precursor, as well as the different ligands $\mathbf{L 0}$ and L1-L4 were also studied and resulted to be non-toxic at the highest tested concentrations in both cell lines. Representative values are reported in Table 2 for $\mathbf{L O}$. 
Table 2. Antiproliferative activity ( $E_{50}$ values) of different cages and cage:cisplatin (1:2) formulations in human A375 and A549 cancer cells compared to cisplatin after $24 \mathrm{~h}$ incubation.

\begin{tabular}{|c|c|c|}
\hline & \multicolumn{2}{|c|}{$\mathrm{EC}_{50}[\mu \mathrm{M}]^{[\mathrm{a}]}$} \\
\hline Treatment & $\begin{array}{c}\text { A375 (melanoma) } \\
\alpha \mathrm{V} \beta 3++\end{array}$ & $\begin{array}{c}\text { A549 (lung) } \\
\alpha \vee \beta 3-\end{array}$ \\
\hline Ligand LO & $>50$ & $>100$ \\
\hline cage $\mathbf{C O}$ & $>50$ & $82.6 \pm 15.1^{[b]}$ \\
\hline [cisplatin $\subset(\mathbf{C} 0)$ ] & $31.5 \pm 3.0$ & $>60$ \\
\hline cage $\mathbf{C} 1$ & $>50$ & $>60$ \\
\hline [cisplatin $\subset(\mathbf{C} 1)]$ & $32.4 \pm 1.2$ & $>60$ \\
\hline cage $\mathbf{C 2}$ & $>50$ & $>60$ \\
\hline [cisplatin $\subset(\mathbf{C 2})]$ & $15.80 \pm 3.35^{\star}$ & $>60$ \\
\hline cage C3 & $>50$ & $>60$ \\
\hline [cisplatin $\subset(\mathbf{C} 3)$ ] & $29.5 \pm 0.6$ & $>60$ \\
\hline cisplatin & $33.9 \pm 2.9$ & $63.2 \pm 5.2$ \\
\hline
\end{tabular}

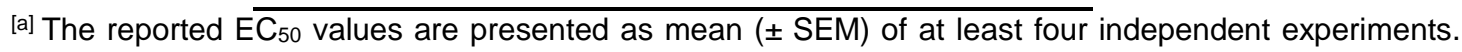
[b] Value taken from reference [12]. ${ }^{*}(p<0.01)$ indicate the difference is significant when compared to samples treated with cisplatin only.

In order to constitute an optimal drug delivery system, metallacages should be deprived of intrinsic toxic effects in normal tissues, and preferably reduce the toxicity exerted by the encapsulated drug. Thus, as proof of concept, cage $\mathbf{C} \mathbf{0}$, alone or encapsulating cisplatin, was tested for its toxicity on healthy rat kidney and liver tissues ex vivo using the precision-cut tissue slices (PCTS) technique.46-50 PCTS are thin $(150-250 \mu \mathrm{m})$ slices of viable tissue. In this model, all cells remain in their natural environment maintaining the original cell-cell and cell-matrix contacts, which are absent in classical 2D cell cultures in vitro. This method is a FDA-approved model for drug toxicity and metabolism studies, and is also useful to determine drug uptake/efflux mechanisms. ${ }^{46-50}$ Recently, we have successfully used the PCTS method to study the toxic effects of experimental anticancer organometallic compounds, including aminoferrocene-containing prodrugs, ruthenium-based kinase inhibitors, as well as gold(l) carbenes and gold(III) cyclometalated cytotoxic agents. ${ }^{46-50}$

Thus, the viability of the liver and kidney slices was determined by incubating the PCTS with different concentrations of cage $\mathbf{C O}$, alone or encapsulating cisplatin (cage:cisplatin =1:2), for $24 \mathrm{~h}$ and measuring the ATP/protein content (see SI for details). Cisplatin was also administered in the same range of concentrations for comparison. The obtained results for liver and kidney are presented in Fig. 3 (A and B). As expected, and in line with previous results, ${ }^{49}$ cisplatin alone causes a marked reduction of slice viability in both organs. Instead, cage $\mathbf{C O}$ was substantially not toxic even at the highest tested 
concentration in the liver slices. Ligand $\mathbf{L} 0$ and the $\mathrm{Pd}^{2+}$ precursor were also non-toxic above $100 \mu \mathrm{M}$ (data not shown). Of note, encapsulated cisplatin showed a significantly reduced toxicity in both liver and kidney slices compared to free cisplatin.
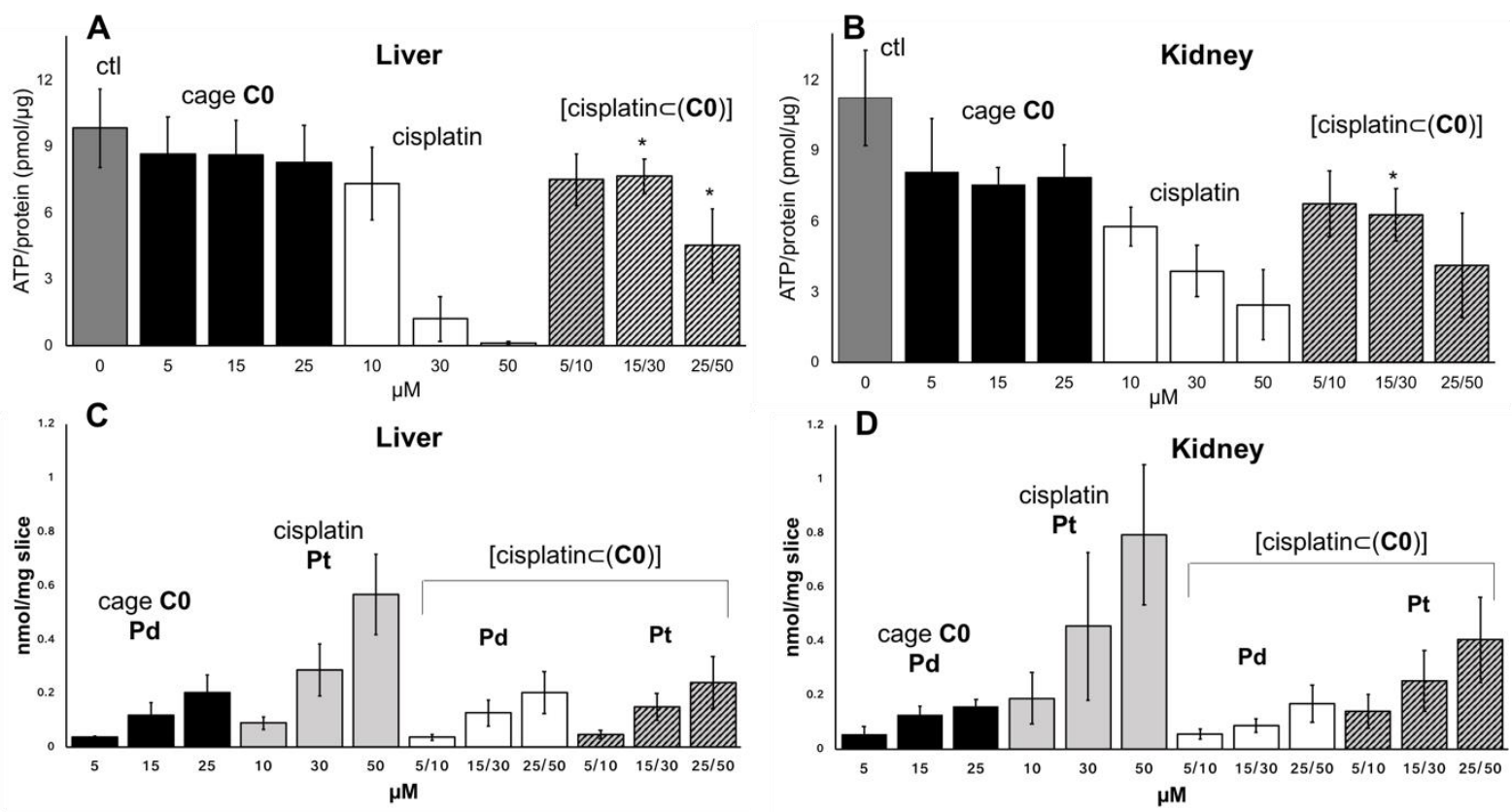

Figure 3 - A and B: Viability of Precision Cut Tissue Slices (PCTS) from liver (A) and kidney (B), treated for $24 \mathrm{~h}$ with different concentrations of cisplatin $(5,10$ and $25 \mu \mathrm{M})$, cage $\mathbf{C O}(10,30$ and $50 \mu \mathrm{M})$ and encapsulated cisplatin [cisplatin $\subset(\mathbf{C O})$ ] ([cage]/[cisplatin] $=5 / 10,15 / 30,25 / 50 \mu \mathrm{M})$. C and D: Total metal content (Pd and Pt) determined by ICP-MS in PCTS of liver (C) and kidney (D) treated for $24 \mathrm{~h}$ with different concentrations of cisplatin, cage $\mathbf{C O}$ and encapsulated cisplatin ([cisplatin $\subset(\mathbf{C O})]$ ). The error bars show the standard deviation of at least three independent experiments. For statistical analysis the Two Independent Sample t-Test was applied. * $(p \leq 0.01)$ indicates the difference is significant when compared to its control (treatment with cisplatin at the same concentration).

In order to evaluate the relation between toxicity and intracellular metal accumulation, we determined the Pt and Pd content of tissue slices exposed to cisplatin alone or encapsulated in cage Co by ICP-MS. Thus, PCTS were incubated for $24 \mathrm{~h}$ in the same conditions as for the ATP determination described above. In PCTS, the metal concentration increases in a concentration dependent manner (Fig. 3, C and D). Overall, as expected, ${ }^{51}$ the Pt content is higher in kidney (Fig. 3D) than in liver (Fig. 3C). However, the accumulation of Pd is somewhat higher in the liver than in the kidney PCTS. Moreover, the results suggest that $\mathrm{Pd}$ accumulation is not influenced by cisplatin encapsulation. As it can be observed in Fig. 3C, in the case of liver slices, cisplatin encapsulated in cage $\mathbf{C O}$ is markedly less accumulated than free cisplatin. Similar conclusions can be made for kidney samples although the differences are not as significant (Fig. 3D). Thus, the obtained results are another indirect evidence that cisplatin encapsulation in the metallacage is mostly preserved even in biological environment. 
In the liver, the content of $\mathrm{Pd}$ and $\mathrm{Pt}$ in the [cisplatin $\subset(\mathbf{C O})$ ] treated slices is roughly in accordance with the predicted metal stoichiometry (Pd:Pt). However, in the kidney, the Pt content is higher than the Pd content, and this result should be further investigated. Possibly, Pd is partly excreted from the tissue over $24 \mathrm{~h}$, while Pt is not (or less). Alternatively, a part of cisplatin may be released from the cage before uptake and enter the tissue more efficiently than in the liver. In this latter case the overall Pt content may be the result of accumulation of both encapsulated and free cisplatin. However, this latter explanation may be less likely in liver as such an effect is not seen in this organ.

In conclusion, we herein present an integrin selective supramolecular drug delivery system for cisplatin based on the $\mathrm{Pd}_{2} \mathrm{~L}_{4}$ metallacage scaffold. Encapsulation of cisplatin in the RGD-modified metallacage exhibits increased anticancer effects in vitro, and the metallacaged cisplatin itself has a decreased toxicity against healthy tissues ex vivo. The latter observation is explained on the basis of reduced platinum uptake in healthy tissues. Although further studies are necessary to fully characterize the properties of metallacages as drug delivery systems, including their stability in physiological conditions and drug release properties, toxicity of cages conjugated with integrin ligands in healthy tissue, as well as study of the effects in in vivo models, our work constitutes a first proof-of-concept of the possible use of supramolecular coordination complexes for directed drug delivery. 


\section{Experimental}

\section{Synthesis}

\section{Synthesis and analysis of ligand $\mathbf{L O}$}

Ligand $\mathbf{L O}$ has been synthesised adapting a previously reported procedure, ${ }^{12}$ to increase the overall yield and including a protecting step of the carboxylic moiety (Scheme S1). The starting compound benzyl 3,5-dibromobenzoate was synthesised according to a previously reported procedure by benzyl protection of 3,5-dibromobenzoic acid, ${ }^{52}$ and fully characterized by NMR (see supplementary information for details and Figures S1-S6).

\section{Synthesis of ligands 1-4}

In this section we report the general procedures (GPs) for the synthesis of the integrin binding ligands. For details and analysis, we refer to the supplementary material.

GP1 Loading of TCP-resin. Peptide synthesis was carried out using 2-chlorotrityl chloride resin (2-CTCresin) $(0.9 \mathrm{mmol} / \mathrm{g})$ following standard Fmoc-strategy. Fmoc-Xaa-OH (1.20 eq.) were attached to the resin with DIPEA (2.50 eq.) in anhydrous $\mathrm{CH}_{2} \mathrm{Cl}_{2}(10 \mathrm{~mL} / \mathrm{g}$ resin) for $2 \mathrm{~h}$ at r.t. Remaining 2-chlorotrityl chloride groups were capped by adding a mixture of $\mathrm{MeOH}$, DIPEA $(5: 1 ; v / v ; 1.0 \mathrm{~mL} / \mathrm{g}$ resin) for $15 \mathrm{~min}$. The resin was then filtered and washed with $\mathrm{CH}_{2} \mathrm{Cl}_{2}(5 \mathrm{x})$ and $\mathrm{N}$-methylpyrrolidon (NMP; 3x). The loading capacity was estimated to be $0.9 \mathrm{mmol} / \mathrm{g}(100 \%)$.

GP2 On-Resin Fmoc Deprotection. The resin-bound Fmoc peptide was treated with 20\% ( $/ \mathrm{v})$ piperidine in NMP twice (1x10 min, 1x5 min) and subsequently washed with NMP (5x).

GP3 Standard Amino Acid Coupling. A solution of Fmoc-Xaa-OH (2.00 eq.), O-(7-azabenzotriazol-1-yl)$N, N, N, N$-tetramethyluronium-hexafluorphosphate (HATU) (2.00 eq.), 1-hydroxybenzotriazole (HOBt; 2.00 eq.), and DIPEA (5.00 eq.) in NMP (10 mL/g resin) was added to the resin-bound free amine peptide and shaken for 60 min at r.t. The resin was then washed with NMP (5x).

GP4 Cleavage of Linear Peptides from the Resin. For complete cleavage from the resin, the peptides were treated with a solution of $\mathrm{CH}_{2} \mathrm{Cl}_{2}$ and hexafluoroisopropanol (HFIP; $\left.4: 1 ; v / v\right)$ for 15 min at r.t. (2x). The solvent was then evaporated under reduced pressure.

GP5 Peptide cyclization. To a solution of linear peptide in DMF (2 $\mathrm{mm}$ peptide concentration) and $\mathrm{NaHCO}_{3}$ (5.00 eq.) diphenylphosphoryl azide (DPPA; 3.00 eq.) was added at r.t. and stirred until completion of cyclization was observed (monitored by HESI-MS, usually over night). The solvent was evaporated in vacuo and the crude material directly used for the next step. 
GP6 Cbz-deprotection in solution. The Cbz-protected starting material was dissolved in $\mathrm{MeOH}(0.15 \mathrm{~m})$, Pd on carbon (0.02 eq. 10 wt.\%, dry) was added and hydrogen bubbled through the reaction mixture. Reaction progress was monitored by HESI-MS-analysis. After complete deprotection (usually 1-3 h) the reaction mixture was filtrated over Celite and the solid residue was washed with $\mathrm{MeOH}$. The solvent was removed in vacuo.

GP7 Coupling in Solution. The free amine was dissolved in DMF ( 0.1 mol/L) and the acid (1.20 eq.), HATU (1.20 eq.), HOBt (1.20 eq.) and DIPEA (3.00 eq.) were added and the solution stirred over night or until no residual free amine could be observed (monitored by HESI-MS). After removal of the solvent in vacuo, the residue was taken up in $\mathrm{EtOAc}$, washed with $\mathrm{HCl}_{\text {aq. }}(1 \mathrm{M}, 2 \mathrm{x})$ and brine. The organic phase was dried over $\mathrm{Na}_{2} \mathrm{SO}_{4}$, filtrated and the solvent removed in vacuo. The isolated products were purified via RP-HPLC or used as crude starting material for the next reaction step.

GP8 Removal of acid-labile side-chain protecting groups: Cyclized peptides were stirred in a solution of TFA, $\mathrm{CH}_{2} \mathrm{Cl}_{2}$, water and TIPS (80-50:15-45:2.5:2.5; $\left.v / v / v\right)$ at r.t. until complete deprotection (approx. $1 \mathrm{~h}$, monitored by HESI-MS). The reaction was quenched by addition of toluene and the solvent mixture was evaporated under reduced pressure $(2 x)$.

GP9 On-resin N-methylation. The Fmoc-deprotected peptide was washed with $\mathrm{CH}_{2} \mathrm{Cl}_{2}(3 \mathrm{x})$, a solution of 2-nitrobenzenesulfonylchloride (4.00 eq.) and 2,4,6-collidine (10.0 eq.) in $\mathrm{CH}_{2} \mathrm{Cl}_{2}$ was added and mixed for 20 min at r.t. The resin was washed with $\mathrm{CH}_{2} \mathrm{Cl}_{2}(3 \mathrm{x})$ and THF abs. (5x). A solution containing $\mathrm{PPh}_{3}$ (5.00 eq.) and $\mathrm{MeOH}$ abs. (10.0 eq.) in THF abs. was added to the resin. DIAD (5.00 eq.) in a small amount THF abs. was added stepwise to the resin and mixed for $15 \mathrm{~min}$ at r.t. The resin was subsequently washed with THF (5x) and NMP (5x). For o-Ns deprotection, the resin-bound o-Nspeptides were stirred in a solution of mercaptoethanol (10.0 eq.) and DBU (5.00 eq.) in NMP (10 mL/g resin) for $5 \mathrm{~min}$ at r.t. The deprotection procedure was repeated once and the resin was subsequently washed with NMP $(5 x)$.

GP10 Dde-deprotection in solution. The orthogonal deprotection of Dde was performed using a solution of hydrazine hydrate (2 vol.- $\%$ ) in DMF for 30 min at r.t. The progress of the reaction was monitored by HESI-MS. After completion of the reaction, the solvent was removed under reduced pressure.

GP11 Boc-, ${ }^{t} B u$-deprotection in solution. The starting material was dissolved in $\mathrm{CH}_{2} \mathrm{Cl}_{2}(\sim 1 \mathrm{~mL} / 100 \mathrm{mg})$ and an equal volume of TFA added at r.t. The solution was stirred for 30-60 min. The reaction was quenched by the addition of toluene and the solvent was evaporated under reduced pressure. The latter step was repeated once. 


\section{$\underline{\text { Synthesis of ligands L1-L4 }}$}

3,5-bis(pyridin-3-ylethynyl)benzoic acid (1.00 eq.), HATU (O-(7-azabenzotriazol-1-yl)- $N, N, N^{\prime}, N^{\prime}$ tetramethyluronium-hexafluorophosphate, 1.00 eq.) and $\mathrm{HOBt}$ (1-hydroxybenzotriazole, 1.00 eq.) were dissolved in DMF (50 mM, referred to 1.00 eq.) and DIPEA ( $N, N$-diisopropylethylamine, 2.00 eq.) was added. The solution was stirred at room temperature for $20 \mathrm{~min}$ and subsequently added to a solution of the corresponding amine (50 mM in DMF, 1.00 eq.) in DMF. The reaction mixture was stirred for $1 \mathrm{~h}$ at r.t., the solvent was removed in vacuo and the crude product was purified via semi-preparative RPHPLC. For details and analysis, we refer to the supplementary material.

\section{Synthesis of cage $\mathbf{c o}$}

A solution of $\left[\mathrm{Pd}\left(\mathrm{NCCH}_{3}\right)_{4}\right]\left(\mathrm{BF}_{4}\right)_{2}(22.2 \mathrm{mg}, 0.05 \mathrm{mmol}, 2.00$ equiv.) and ligand $\mathbf{L O}$ (32.4 mg, $0.10 \mathrm{mmol}$, 4.00 equiv.) in DMSO was stirred for $1 \mathrm{~h}$ at room temperature (Scheme S3). Following precipitation by addition of acetone and diethyl ether, the solid was then filtrated and washed with diethyl ether to yield the cage compound as an off-white solid $(42.0 \mathrm{mg}, 23.0 \mu \mathrm{mol}, 92 \%)$. The product was characterized by NMR spectroscopy and high-resolution mass spectrometry (Figures S7-S9).

\section{Synthesis of cages $\mathbf{C 1 - C 4}$}

Synthesis of cages $\mathbf{C 1 - C 4}$ was achieved by self-assembly adapting the procedure reported for cage $\mathbf{C 0}$ described above. The starting material (compounds L1-L4, $\sim 2 \mu \mathrm{mol}, 4.00$ eq.) was weighed into an NMR-tube, respectively, and solubilized in DMSO- $\mathrm{d}_{6}(0.4 \mathrm{~mL})$. A solution of $\mathrm{Pd}(\mathrm{MeCN})_{4}\left(\mathrm{BF}_{4}\right)_{2}$ in DMSO$\mathrm{d}_{6}$ (20.54 mM, 2.00 eq.) was added to the solution in the NMR-tube and homogenized. In the ${ }^{1} \mathrm{H}-\mathrm{NMR}$, the starting material was completely converted to the corresponding metallacage (C1-C4). For the ligands L1, L3 and L4 the molecular weight was calculated as one-fold TFA-salts, for ligand L2 a calculation without TFA-salt gave full consumption of the starting material. Due to their chromatographic instability, the formation procedure was optimized in NMR-solvent (DMSO- $\mathrm{d}_{6}$ ) and analyzed without isolating the product. Hereafter ELISA-assays were performed directly with these solutions. ${ }^{1} \mathrm{H}$-NMRs are shown in Figure 2 and Figures S10-S20 of the Supplementary Information. 


\section{Titration of $\mathrm{Pd}(\mathrm{MeCN})_{4}\left(\mathrm{BF}_{4}\right)_{2}$ to a solution of ligand $\mathbf{L} 4$.}

The exclusively tetrameric cage formation of $\mathbf{C} 4\left(\mathrm{Pd}_{2} \mathrm{~L}_{4}\right)$ is proven by a titration experiment. To a solution of ligand $\mathbf{L} 4\left(2.89 \mathrm{mg}, 2.89 \mu \mathrm{mol}, 4.00 \mathrm{eq}\right.$.) in $\mathrm{DMSO}-\mathrm{d}_{6}(0.4 \mathrm{~mL})$ a solution of $\mathrm{Pd}\left(\mathrm{MeCN}_{4}\left(\mathrm{BF}_{4}\right)_{2}\right.$ $\left(14.3 \mathrm{mM}\right.$ ) in DMSO- $\mathrm{d}_{6}$ was added in four portions (each $0.36 \mu \mathrm{mol}, 23.8 \mu \mathrm{L}$ ). After each addition a ${ }^{1} \mathrm{H}-$ NMR spectrum was measured (see Figure 2).

\section{Encapsulation studies}

\section{$\underline{1 H-N M R \text { spectroscopy }}$}

The benzoate protected $\mathrm{Pd}_{2} \mathrm{~L}_{4}$ cage $\mathbf{C 0}-\mathbf{B z}$ ( $8 \mathrm{mg}, 36 \mu \mathrm{mol}, 1.00$ eq.) was dissolved in $\mathrm{DMF}-\mathrm{d}_{7}(1 \mathrm{~mL})$ and the ${ }^{1} \mathrm{H}-\mathrm{NMR}(500 \mathrm{MHz}, 64$ scans) spectrum was recorded. Cisplatin (2 mg, $72 \mu \mathrm{mol}, 2.00$ eq.) was added and the yellow solution was stirred for $10 \mathrm{~min}$. The ${ }^{1} \mathrm{H}-\mathrm{NMR}$ ( $500 \mathrm{MHz}, 64$ scans) spectrum of the sample was recorded and compared with the previous one (Figure S21).

\section{$\underline{1 H-D O S Y N M R ~ s p e c t r o s c o p y}$}

The benzoate protected ligand L0-Bz (15.7 mg, $37.9 \mu \mathrm{mol}, 4.00$ eq.) was dissolved in DMF- $\mathrm{d}_{7}$ (2.63 mL, $14.4 \mathrm{mM})$ and a solution of $\mathrm{Pd}(\mathrm{MeCN})_{4}\left(\mathrm{BF}_{4}\right)_{2}(8.41 \mathrm{mg}, 18.9 \mu \mathrm{mol}, 2.00$ eq. $)$ in DMF-d $(461 \mu \mathrm{L}$, 41.1 $\mathrm{mM})$ was added and a ${ }^{1} \mathrm{H}-\mathrm{NMR}(400 \mathrm{MHz})$ spectrum was measured to ensure cage-formation. For each ratio, cisplatin was exactly measured out in a glass vial and the previously prepared cage solution was added to get a final cage:cis-Pt ration of 1:1, 1:2, 1:3. The solution was mixed for about 5 min to guarantee complete dissolution of cisplatin, subsequently a ${ }^{1} \mathrm{H}-\mathrm{NMR}$ and a DOSY-NMR was measured (Figure S22-S26).

\section{Integrin binding studies}

The affinity and selectivity of integrin ligands were determined by a solid-phase binding assay applying a previously described protocol ${ }^{37}$ that involves coated extracellular matrix (ECM) proteins and soluble integrins. The following compounds were used as internal standards: cilengitide $e^{29}, c(f(M M e) V R G D)$ $(\alpha v \beta 3-0.54 \mathrm{nM}, \alpha v \beta 5-8 \mathrm{nM}, \alpha 5 \beta 1-15.4 \mathrm{nM})$. Flat-bottomed 96-well ELISA plates (BRAND, Wertheim, Germany) were coated overnight at $4{ }^{\circ} \mathrm{C}$ with ECM protein (1) $(100 \mu \mathrm{L}$ per well) in carbonate buffer (15 mM Na $\mathrm{CO}_{3}, 35 \mathrm{mM} \mathrm{NaHCO}_{3}$, pH 9.6). Afterwards, each well was washed with PBS-T buffer (phosphate-buffered saline/Tween 20, $137 \mathrm{mM} \mathrm{NaCl}, 2.7 \mathrm{mM} \mathrm{KCl}, 10 \mathrm{mM} \mathrm{Na}_{2} \mathrm{HPO}_{4}, 2 \mathrm{mM} \mathrm{KH}_{2} \mathrm{PO}_{4}$, $0.01 \%$ Tween 20, pH 7.4; $3 \times 200 \mu \mathrm{L}$ ) and blocked for $1 \mathrm{~h}$ at room temperature with TS-B buffer (Trissaline/bovine serum albumin (BSA) buffer, $20 \mathrm{mM}$ Tris- $\mathrm{HCl}, 150 \mathrm{mM} \mathrm{NaCl}, 1 \mathrm{mM} \mathrm{CaCl}, 1 \mathrm{mM} \mathrm{MgCl}$, 
$1 \mathrm{mM} \mathrm{MnCl} 2, \mathrm{pH} 7.5,1 \% \mathrm{BSA} ; 150 \mu \mathrm{L} /$ well). Meanwhile, a dilution series of the compounds and internal standard was prepared in an extra plate, ranging from $20 \mu \mathrm{M}$ to $256 \mathrm{pM}$ in 1:5 dilution steps. After washing the assay plate three times with PBS-T $(200 \mu \mathrm{L}), 50 \mu \mathrm{L}$ aliquots of the dilution series were transferred to each well from B-G in 6 appropriate concentrations. Well A was filled with $100 \mu \mathrm{L}$ of TSB solution (blank), and well $\mathrm{H}$ was filled with $50 \mu \mathrm{l}$ of TS-B buffer. Then, $50 \mu \mathrm{l}$ of a solution of human integrin (2) in TS-B buffer was transferred to wells $\mathrm{H}-\mathrm{B}$ and incubated for $1 \mathrm{~h}$ at r.t. The plate was washed three times with PBS-T buffer, and then primary antibody (3) $(100 \mu \mathrm{L}$ per well) was added to the plate. After incubation for $1 \mathrm{~h}$ at r.t., the plate was washed three times with PBS-T. Then, secondary peroxidase-conjugated antibody (4) $(100 \mu \mathrm{L} /$ well) was added to the plate and incubated for $1 \mathrm{~h}$ at r.t. Details on the respective solutions (1-4) for each integrin ligand are provided in the supplementary material. The plate was then washed three times with PBS-T, developed by the addition of SeramunBlau (50 $\mu \mathrm{L} /$ well, Seramun Diagnostic $\mathrm{GmbH}$, Heidesee, Germany) and incubated for approx. 1 min at r.t. in the dark. The reaction was stopped with $3 \mathrm{M} \mathrm{H}_{2} \mathrm{SO}_{4}(50 \mu \mathrm{L} /$ well), and the absorbance was measured at $450 \mathrm{~nm}$ with a plate reader (infinite M200 Pro, TECAN). The $\mathrm{IC}_{50}$ value of each compound resulted from a sigmoidal fit of two data rows (serial dilution rows) done by OriginPro 9.0G statistical software. All IC 50 values were referenced to the affinity of the internal standard.

\section{Antiproliferative assays}

Human malignant melanoma cancer cell line A375 and human lung cancer cell line A549 were obtained from ATCC and maintained in culture as described by the provider. The cells were cultured in DMEM (Dulbecco`s Modified Eagle Medium, Corning), supplemented with 10\% fetal bovine serum (FBS, Euapproved South American Origin, Thermo Fisher Scientific) and 1\% penicillin/ streptomycin (Gibco) at $37^{\circ} \mathrm{C}$ and $5 \% \mathrm{CO}_{2}$.

To monitor the self-assembly of the cages $\mathbf{C 0}-\mathbf{C} 4$ from ligands L0-L4 and to study the subsequent cisplatin encapsulation, ${ }^{1} \mathrm{H}$ NMR studies were conducted directly in $\mathrm{DMSO} / \mathrm{H}_{2} \mathrm{O}$ with a capillary of $\mathrm{CDCl}_{3}$ (so the solution could then directly be used for further biological studies). Thus, each cage was dissolved in $1 \mathrm{~mL}$ of $\mathrm{DMSO}$ ( $\max 20 \%$ ) in $\mathrm{H}_{2} \mathrm{O}$ (stock solution $3 \mathrm{mM}, 1$ eq.) and added to a NMR tube containing a closed capillary of $\mathrm{CDCl}_{3}$. Only in the case of the poorly soluble cage $\mathbf{C} 0$ the initial stock solution 3 mM was prepared in 100\% DMSO. ${ }^{1} \mathrm{H}$ NMR spectra were recorded before and after addition of 2 eq. of cisplatin to assess drug encapsulation. After confirmation of the encapsulation process, the solution was then extracted from the NMR tube and further diluted for the cell viability studies $(0.1$ to $60 \mu \mathrm{M})$ in DMEM 
medium. The maximal tested DMSO concentration was $0.1 \%$, except than in the case of the least soluble cage $\mathbf{C 0}(0.5 \%)$. In this latter case, control experiments with different concentration of DMSO were conducted to exclude possible effects on cells viability. Concentrations higher than $50 \mu \mathrm{M}$ were not tested in A375 cells to avoid toxic effects of DMSO. Cisplatin (Sigma-Aldrich) was used as reference compound (tested between 0.1 to $100 \mu \mathrm{M}$ ), and its stock dilutions ( $1 \mathrm{mM}$ ) were freshly prepared in aqueous solution prior each experiment. For evaluation of cell growth inhibition, cells were seeded in 96-well plates (Corning) at a concentration of 15000 cells/well and grown for $24 \mathrm{~h}$ in $200 \mu \mathrm{L}$ complete medium. After $24 \mathrm{~h}$ incubation, $200 \mu \mathrm{L}$ of the compounds' dilutions were added to each well and the cells were incubated for additional $24 \mathrm{~h}$. Afterwards, the medium was removed and 3-(4,5dimethylthiazol-2-yl)-2,5-diphenyltetrazolium bromide (MTT, Fluorochem) in 10x PBS (Phosphate Buffered Saline, Corning) was added to the cells, at a final concentration of $0.3 \mathrm{mg} / \mathrm{mL}$ and incubated for 3-4 h. Then, the MTT solution was discarded and replaced with DMSO to allow the formed violet formazan crystals to dissolve. The optical density was quantified in quadruplicate at $550 \mathrm{~nm}$ using a multi-well plate reader. The percentage of surviving cells was calculated from the ratio of absorbance of treated to untreated cells. The $\mathrm{EC}_{50}$ value was calculated, using GraphPad Prism software, as the concentration causing $50 \%$ decrease in cell viability, using a nonlinear fitting of cell viability vs [treatment], and presented as mean \pm SEM of at least three independent experiments. Statistical testing was performed using a Two Sample t-Test, to compare the [cisplatinc $(\mathbf{C} \mathbf{0}-\mathbf{3})]$ treated samples with its control samples (treatment with cisplatin at the same concentration). A $p$-value of $\leq 0.01$ was considered to be significant.

\section{Ex vivo studies}

Male Wistar rats (Charles River, France) of 250-300 g were housed under a $12 \mathrm{~h}$ dark/light cycle at constant humidity and temperature. Animals were permitted ad libitum access to tap water and standard lab chow. All experiments were approved by the committee for care and use of laboratory animals of the University of Groningen and were performed according to strict governmental and international guidelines.

Livers and kidneys were harvested (from rats anesthetized with isoflurane) and immediately placed in University of Wisconsin solution (UW, Dupont Critical Care, Waukegan, IL, USA, $4^{0} \mathrm{C}$ ) until further use. For livers, cylindrical cores of 5 mm diameter were made using a Schlagbohrer Bosch (3 603 A 26 200). The kidneys, after removal of fat were cut in half lengthwise using a scalpel, and cores of $5 \mathrm{~mm}$ diameter 
were cut from the kidney cortex from each half perpendicular to the cut surface using disposable Biopsy Punches (KAI medical, Japan). Precision-cut liver slices (PCLS, diameter $5 \mathrm{~mm}$; thickness $250 \mu \mathrm{m}$; weight $5 \mathrm{mg}$;) and precision-cut kidney slices (PCKS, diameter $5 \mathrm{~mm}$; thickness $150 \mu \mathrm{m}$; weight $3 \mathrm{mg}$;) were sliced with a Krumdieck tissue slicer (TSE, Bad Homburg, Germany) in ice-cold Krebs buffer at pH 7.42 , enriched with glucose to a final concentration of $25 \mathrm{mM}$ and saturated with carbogen $\left(95 \% \mathrm{O}_{2} / 5 \%\right.$ $\left.\mathrm{CO}_{2}\right) \cdot{ }^{44} \mathrm{PCLS}$ and PCKS were immediately moved to ice-cold UW and stored on ice until the beginning of the experiment for maximally $3 \mathrm{~h}$. PCLS and PCKS were preincubated individually at $37^{\circ} \mathrm{C}$ for $1 \mathrm{~h}$ in 12-well plates in $1.3 \mathrm{~mL}$ of Williams Medium E (WME, Gibco by Life Technologies, UK) with glutamax1 (Gibco, Invitrogen, Paisley, Scotland) supplemented with 25 mM D-glucose, supplemented with 50 $\mu \mathrm{g} / \mathrm{mL}$ gentamycin (Gibco, Invitrogen, Paisley, Scotland) for PCLS and with ciprofloxacin $\mathrm{HCl}(10 \mu \mathrm{g} / \mathrm{mL}$, Sigma-Aldrich, Steinheim, Germany) for PCKS. In the incubator (Sanyo $\mathrm{CO}_{2} / \mathrm{O}_{2}$ Incubator, PANASONIC, Secaucus, NJ, USA), the plates were under $80 \% \mathrm{O}_{2}$ and $5 \% \mathrm{CO}_{2}$ atmosphere, while being gently shaken (90 times/min). Preincubation allows the slices to restore the ATP levels ${ }^{44}$ and is helpful to remove debris and dead cells before the start of the experiments. After preincubation, the slices were moved to different well plates filled with $1.3 \mathrm{~mL}$ of prewarmed complete WME medium and different concentrations of the tested compounds and incubated for $24 \mathrm{~h}$. The final concentrations of tested compounds are: Cage $\mathbf{C O}=5 \mu \mathrm{M}, 15 \mu \mathrm{M}$ and $25 \mu \mathrm{M}$ with $0.83 \% \mathrm{DMSO} v / \mathrm{v}$; cisplatin $=10 \mu \mathrm{M}$, $30 \mu \mathrm{M}$ and $50 \mu \mathrm{M}$; [cisplatin $\subset(\mathbf{C O})]=$ [cisplatin]:[cage] of $5 / 10 \mu \mathrm{M}, 15 / 30 \mu \mathrm{M}$ and $25 / 50 \mu \mathrm{M}$ with $0.83 \%$ DMSO v/v. For the final concentration of [cisplatin $\subset(\mathbf{C O})]$. Experiments were performed in triplicate using at least 3 individual rat organs. For each treatment, three slices were used to assess the ATP content. It is important to note that the PCLS and PCKS of each liver/kidney sample were exposed to all three compounds, as well as controls, in order to limit the influence of non-biological experimental variation. This experimental design helps to limit interindividual variation between compound's classes, as well as between compounds and controls, in the data set.

\section{Evaluation of ATP content}

After PCTS pre-incubation, different concentrations of cisplatin and cage $\mathbf{C} \mathbf{0}$ or of encapsulated cisplatin [cisplatin $\subset(\mathbf{C O})]$ were added to the wells and the slices were incubated for $24 \mathrm{~h}$. Afterwards, slices were collected for ATP and protein determination, by snap freezing in $1 \mathrm{~mL}$ of ethanol $(70 \% \mathrm{v} / \mathrm{v})$ containing 2 $\mathrm{mM}$ EDTA with $\mathrm{pH}=10.9$. After thawing, the slices were homogenized using a mini-bead beater and centrifuged. The supernatant was used for the ATP essay and the pellet was dissolved in $5 \mathrm{M} \mathrm{NaOH}$ for 
the protein assay. ATP was measured using the ATP Bioluminescence Assay kit CLS II (Roche, Mannheim, Germany). The ATP content was corrected by the protein amount of each slice and expressed as pmol/ $\mathrm{\mu g}$ protein. The protein content of the PCTS was determined by the Bio-Rad DC Protein Assay (Bio-Rad, Munich, Germany) using bovine serum albumin (BSA, Sigma-Aldrich, Steinheim, Germany) for the calibration curve.

\section{$\underline{\text { Statistics }}$}

A minimum of three independent experiments were performed using slices in triplicates from each rat tissue. Statistical testing was performed with Two Sample t-Test to compare the [cisplatin $\subset(\mathbf{C O})$ ] treated samples with its control samples (treatment with cisplatin at the same concentration). A p-value of $\leq 0.01$ was considered to be significant.

\section{Metal content determination by ICP MS}

After incubation with the different concentrations of cisplatin, cage $\mathbf{C O}$ or of the cage/cisplatin complex [cisplatin $\subset(\mathbf{C O})$ ], PCTS were washed with ice-cold Krebs-Henseleit buffer and snap-frozen and stored at $-80^{\circ} \mathrm{C}$ until the analysis.

\section{Sample preparation and $P t$ and $P d$ determination}

The tissue samples were digested with $100 \mu \mathrm{L}$ nitric acid overnight, all samples were completely dissolved. $100 \mu \mathrm{L}$ hydrochloric acid and $800 \mu \mathrm{L}$ milliQ were added to produce a volume of $1 \mathrm{~mL}$. Prior to analysis the samples were diluted 20 times with $0.65 \% \mathrm{HNO}_{3} / 0.1 \% \mathrm{HCl}$.

The Pt and Pd contents were quantitated applying a Perkin Elmer (Waltham, MA, USA) Sciex Elan DRCe ICP-MS instrument, equipped with a Cetac ASX-110FR autosampler, a $0.2 \mathrm{~mL}$ min-1 MicroMist Useries pneumatic concentric nebulizer (Glass Expansion, West Melbourne Vic, Australia) and a PC3 cyclonic spray chamber (Elemental Scientific Inc., Omaha, NE, USA). ICP-MS RF power, lens voltage and nebulizer gas and flow were optimized on a daily basis and other settings were: 1 sweep/reading, 25 readings/replicate, 5 replicates, $50 \mathrm{~ms}$ dwell time. The ${ }^{195} \mathrm{Pt}^{+},{ }^{194} \mathrm{Pt}^{+}$and ${ }^{105} \mathrm{Pd}^{+}$isotopes were monitored. Pt and Pd concentrations were determined by external calibration (0-20 ppb Pt and Pd). LODs were $0.1 \mu \mathrm{g} \mathrm{L}^{-1}$ for both $\mathrm{Pt}$ and $\mathrm{Pd},\left(3^{*} \mathrm{SD}\right.$ on blank, $\left.\mathrm{n}=10\right)$ and the spike recovery were $102 \%$ and 99\% for Pt and Pd $(n=3)$, respectively. Pt and Pd single element PlasmaCAL standards (SCP Science, Quebéc, Canada) were used and the standards were prepared in a mixture of $0.1 \% \mathrm{HCl}$ and $0.65 \%$ 
sub-boiled $\mathrm{HNO}_{3}$ in MilliQ water. This mixture was furthermore used to dilute samples after digestion and as blank solution.

\section{Statistics}

A minimum of three independent experiments were performed using slices with triplicates for each condition. The PCLS and PCKS were prepared from three rats and in each experiment slices were exposed in triplicate. The Pt and Pd contents were expressed as $\mathrm{nmol} / \mathrm{mg}$ slice and is presented as a mean $( \pm \mathrm{SD})$ of at least three independent experiments. Pt and Pd concentrations were calculated to compare the [cisplatin $\subset(\mathbf{C O})$ ] treated samples with its control samples (treatment with cisplatin or $\mathbf{C 0}$ at the same concentration).

\section{Acknowledgements}

Authors thank Cardiff University and University of Groningen for funding. A.C. acknowledges the support of the TU München - Institute for Advanced Study, funded by the German Excellence Initiative and the European Union $7^{\text {th }}$ Framework Programme under grant agreement $n^{\circ} 291763$. This work was also supported by CIPSM and a Koselleck grant of the Deutsche Forschungsgemeinschaft (Ke147/42-1). J.H. thanks the China Scholarship Council (CSC) for a PhD fellowship. We thank Prof. Dr. Eisenreich (TU München) for help with DOSY NMR measurements. Authors thank N. Estrada-Ortiz, M. de Jager, V. Starokozhko and R. Bartucci for helping with the slice experiments.

\section{Supporting Information}

The Supporting Information, including experimental details and compounds analysis, as well as results of encapsulation studies by NMR spectroscopy, is available free of charge on the ACS Publications website at DOI: XXXX.

\section{Authors Contributions}

A.C., P. H., H. K. conceptualized the project. A.C. wrote the manuscript, supervised the synthesis of the ligands and cages, and designed the in vitro experiments. G.M.M.G. designed the ex vivo experiments. H.P. and R.B. contributed to the design of the biological experiments, cage analysis and data interpretation. J.H. performed the ex vivo experiments and set-up the first protocol for cage bioconjugation and analysis. A.F.B.R. synthesized the integrin ligands, established the NMR analysis of 
the cages, performed most of the encapsulation studies by NMR and wrote the SI. F.R. synthesized the integrin ligands and performed the in vitro ELISA tests. M.W. established the functionalisation of peptide $\mathbf{3}$ and synthesised L3. B.S.L. was involved in the synthesis of integrin binding ligands. B.A. performed the in vitro experiments. M.N.W. performed some of the encapsulation studies and assisted in the design of the NMR experiments. B.W. optimized the synthesis of ligand L0, synthesized cage $\mathbf{C} \mathbf{0}$ and performed NMR experiments. S. S. performed the ICP MS analysis. All the authors contributed to the writing of the manuscript.

\section{References}

1 T. R. Cook, V. Vajpayee, M. H. Lee, P. J. Stang, K.-W. Chi, Acc. Chem. Res. 2013, 46, 2464-2474.

2 A. Casini, B. Woods, M. Wenzel, Inorg. Chem. 2017, 56, 14715-14729.

3 R. A. Kaner, S. J. Allison, A. D. Faulkner, R. M. Phillips, D. I. Roper, S. L. Shepherd,

D. H. Simpson, N. R. Waterfield, P. Scott, Chem. Sci. 2016, 7, 951-958.

4 D. Preston, S. M. McNeill, J. E. M. Lewis, G. I. Giles, J. D. Crowley, Dalton Trans. 2016, 45, 8050-8060.

5 F. Schmitt, N. P. E. Barry, L. Juillerat-Jeanneret, B. Therrien, Bioorganic Med. Chem. Lett. 2012, 22, 178-180.

6 V. Vajpayee, Y. J. Yang, S. C. Kang, H. Kim, I. S. Kim, M. Wang, P. J. Stang, K.-W. Chi, Chem. Commun. 2011, 47, 5184-5186.

7 A. Ahmedova, D. Momekova, M. Yamashina, P. Shestakova, G. Momekov, M. Akita, M. Yoshizawa, Chem. Asian J. 2016, 11, 474-477.

8 A. Schmidt, A. Casini, F. E. Kühn, Coord. Chem. Rev. 2014, 275, 19 -36.

9 T. R. Cook, Y.-R. Zheng, P. J. Stang, Chem. Rev. 2013, 113, 734-777.

10 J. E. M. Lewis, E. L. Gavey, S. A. Cameron, J. D. Crowley, Chem. Sci. 2012, 3, 778784.

11 H. Burger, W. J. Loos, K. Eechoute, J. Verweij, R. H. Mathijssen, E. A. Wiemer, Drug Resist. Updat. 2011, 14, 22-34.

12 A. Schmidt, M. Hollering, M. Drees, A. Casini, F. E. Kühn, Dalton Trans. 2016, 45, 8556-8565.

13 A. Schmidt, M. Hollering, J. Han, A. Casini, F. E. Kühn, Dalton Trans. 2016, 45, 12297-12300.

14 F. Kaiser, A. Schmidt, W. Heydenreuter, P. J. Altmann, A. Casini, S. A. Sieber, F. E. Kühn, Eur. J. Inorg. Chem. 2016, 2016, 5189-5196. 
15 A. Schmidt, V. Molano, M. Hollering, A. Pöthig, A. Casini, F. E. Kühn, Chem. Eur. J. 2016, 22, 2253-2256.

16 M. L. Hovlid, N. F. Steinmetz, B. Laufer, J. L. Lau, J. Kuzelka, Q. Wang, T. Hyypiä, G. R. Nemerow, H. Kessler, M. Manchester, M. G. Finn, Nanoscale 2012, 4, 3698-3705.

17 J. Han, A. Schmidt, T. Zhang, H. Permentier, G. M. M. Groothuis, R. Bischoff, F. E. Kühn, P. Horvatovich, A. Casini, Chem. Commun. 2017, 53, 1405-1408.

18 K. Ley, J. Rivera-Nieves, W. J. Sandborn, S. Shattil, Nat. Rev. Drug Discovery 2016, 15, 173.

19 M. Nieberler, U. Reuning, F. Reichart, J. Notni, H.-J. Wester, M. Schwaiger, M. Weinmüller, A. Räder, K. Steiger, H. Kessler, Cancers 2017, 9, 116; doi:10.3390/cancers9090116.

20 A. Meyer, J. Auernheimer, A. Modlinger, H. Kessler, Curr. Pharm. Des. 2006, 12, 2723-2747.

21 D. Heckmann, A. Meyer, L. Marinelli, G. Zahn, R. Stragies, H. Kessler, Angew. Chem. Int. Ed. 2007, 46, 3571-3574; Angew. Chem. 2007, 119, 3641-3644.

22 M. Schottelius, B. Laufer, H. Kessler, H.-J. Wester, Acc. Chem. Res. 2009, 42, 969980.

23 F. Rechenmacher, S. Neubauer, J. Polleux, C. Mas-Moruno, M. De Simone, E. A. Cavalcanti-Adam, J. P. Spatz, R. Fässler, H. Kessler, Angew. Chem. Int. Ed. 2013, 52, 1572-1575; Angew. Chem. 2013, 125, 1612-1616.

24 S. Neubauer, F. Rechenmacher, A. J. Beer, F. Curnis, K. Pohle, C. D'Alessandria, H.J. Wester, U. Reuning, A. Corti, M. Schwaiger, H. Kessler, Angew. Chem. Int. Ed. 2013, 52, 11656-11659; Angew. Chem. 2013, 125, 11870-11873.

25 T. G. Kapp, F. Rechenmacher, S. Neubauer, O. V. Maltsev, E. A. Cavalcanti-Adam, R. Zarka, U. Reuning, J. Notni, H.-J. Wester, C. Mas-Moruno, J. Spatz, B. Geiger, H. Kessler, Sci. Rep. 2017, 7, 39805.

26 M. Weinmüller, F. Rechenmacher, U. K. Marelli, F. Reichart, T. G. Kapp, A. F. B. Räder, F. S. Di Leva, L. Marinelli, E. Novellino, J. M. Muñoz-Félix, K. Hodivala-Dilke, A. Schumacher, J. Fanous, C. Gilon, A. Hoffman, H. Kessler, Angew. Chem. Int. Ed. 2017, 56, 16405-16409; Angew. Chem. 2017, 129, 16624-16629.

27 M. Aumailley, M. Gurrath, G. Müller, J. Calvete, R. Timpl, H. Kessler, FEBS Lett. 1991, 291, 50-54.

28 M. A. Dechantsreiter, E. Planker, B. Mathä, E. Lohof, G. Hölzemann, A. Jonczyk, S. L. Goodman, H. Kessler, J. Med. Chem. 1999, 42, 3033-3040.

29 C. Mas-Moruno, F. Rechenmacher, H. Kessler, Anti-Cancer Agents in Med. Chem. 2010, 10, 753-768. 
30 S. Mukhopadhyay, C. M. Barnés, A. Haskel, S. M. Short, K. R. Barnes, S. J. Lippard, Bioconjugate Chem. 2008, 19, 39-49.

31 M. A. Medrano, M. Morais, V. F. C. Ferreira, J. D. G. Correia, A. Paulo, I. Santos, C. Navarro-Ranninger, A. A. Valdes, A. Casini, F. Mendes, A. G. Quiroga, Eur. J. Inorg. Chem. 2017, 2017, 1835-1840.

32 A. Gandioso, E. Shaili, A. Massaguer, G. Artigas, A. González-Cantó, J. A. Woods, P. J. Sadler, V. Marchán, Chem. Commun. 2015, 51, 9169-9172.

33 S. Neubauer, F. Rechenmacher, R. Brimioulle, F. S. Di Leva, A. Bochen, T. R. Sobahi, M. Schottelius, E. Novellino, C. Mas-Moruno, L. Marinelli, H. Kessler, J. Med. Chem. 2014, 57, 3410-3417.

34 D. Heckmann, A. Meyer, B. Laufer, G. Zahn, R. Stragies, H. Kessler, ChemBioChem 2008, 9, 1397-1407.

35 R. Haubner, R. Gratias, B. Diefenbach, S. L. Goodman, A. Jonczyk, H. Kessler, J. Am. Chem. Soc. 1996, 118, 7461-7472.

36 C. Mas-Moruno, R. Fraioli, F. Rechenmacher, S. Neubauer, T. G. Kapp, H. Kessler, Angew. Chem. Int. Ed. 2016, 55, 7048-7067; Angew. Chem. 2016, 128, 7162-7183.

37 A. O. Frank, E. Otto, C. Mas-Moruno, H. B. Schiller, L. Marinelli, S. Cosconati, A. Bochen, D. Vossmeyer, G. Zahn, R. Stragies, E. Novellino, H. Kessler, Angew. Chem. Int. Ed. 2010, 49, 9278-9281; Angew. Chem. 2010, 122, 9465-9468.

38 J. E. Gestwicki, C. W. Cairo, L. E. Strong, K. A. Oetjen, L. L. Kiessling, J. Am. Chem. Soc. 2002, 124, 14922-14933.

39 L. L. Kiessling, J. E. Gestwicki, L. E. Strong, Angew. Chem. Int. Ed. 2006, 45, 23482368; Angew. Chem. 2006, 118, 2408-2429.

40 G. Thumshirn, U. Hersel, S. L. Goodman, H. Kessler, Chem. Eur. J. 2003, 9, 27172725 .

41 Z.-H. Jin, J. Razkin, V. Josserand, D. Boturyn, A. Grichine, I. Texier, M.-C. Favrot, P. Dumy, J.-L. Coll, Molecular Imaging 2007, 6, 43-55.

42 H.-J. Wester, H. Kessler, J. Nucl. Med. 2005, 46, 1940 -1945.

43 Y. Zhang, Y. Sun, F. Yang, J. Guo, J. He, Q. Wu, W. Cao, L. Lv, H. Zheng, Z. Zhang, Viruses 2013, 5, 1114-1130.

44 M. Pisano, D. E. P. I, V. Nieddu, I. Sassu, S. Cossu, G. Galleri, A. Del Gatto, M. Budroni, A. Cossu, M. Saviano, G. Palmieri, L. Zaccaro, C. Rozzo, Anticancer Res. 2013, 33, 871-879.

45 S. L. Goodman, H. J. Grote, C. Wilm, Biol. Open 2012, 1, 329-340.

46 I. A. M. de Graaf, P. Olinga, M. H. de Jager, M. T. Merema, R. de Kanter, E. G. van de Kerkhof, G. M. M. Groothuis, Nat. Protoc. 2010, 5, 1540. 
47 B. Bertrand, L. Stefan, M. Pirrotta, D. Monchaud, E. Bodio, P. Richard, P. Le Gendre, E. Warmerdam, M. H. de Jager, G. M. M. Groothuis, M. Picquet, A. Casini, Inorg. Chem. 2014, 53, 2296-2303.

48 S. Daum, V. F. Chekhun, I. N. Todor, N. Y. Lukianova, Y. V. Shvets, L. Sellner, K. Putzker, J. Lewis, T. Zenz, I. A. M. de Graaf, G. M. M. Groothuis, A. Casini, O. Zozulia, F. Hampel, A. Mokhir, J. Med. Chem. 2015, 58, 2015-2024.

49 S. Spreckelmeyer, N. Estrada-Ortiz, G. G. H. Prins, M. van der Zee, B. Gammelgaard, S. Stürup, I. A. M. de Graaf, G. M. M. Groothuis, A. Casini, Metallomics 2017, 9, 1786-1795.

50 N. Estrada-Ortiz, F. Guarra, I. A. M. de Graaf, L. Marchetti, M. H. de Jager, G. M. M. Groothuis, C. Gabbiani, A. Casini, ChemMedChem 2017, 12, 1429-1435.

51 S. Spreckelmeyer, C. Orvig, A. Casini, Molecules 2014, 19, 15584.

52 S. A. L. Rousseaux, J. Q. Gong, R. Haver, B. Odell, T. D. W. Claridge, L. M. Herz, H. L. Anderson, J. Am. Chem. Soc. 2015, 137, 12713-12718. 